\title{
MODOS E MODAS DA DOENÇA E DO CORPO
}

\author{
Sebastião Jorge Chammé*
}

\begin{abstract}
Resumo: O presente artigo busca compreender o processo da "Construção Social da Saúde" levando-se em consideração que a saúde, no decorrer da hisțória dos homens, foi sempre considerada um "bem" e, por isso, mereceu constante preocupação, no sentido de tornar-se geradora de modas, de modos de fazer e de existir, de conflitos, dualidades e controle social. No decorrer desse tempo, modelos de saúde foram sendo criados, interpretados e recriados, quando necessário, provocando igual processo de transformação nas maneiras de sentir, pensar e agir da população usuária dos mais variados recursos de saúde disponiveis, segundo as relações entre o "mágico e o necessário", estabelecendo, entre os que serviam e os que eram servidos, uma relação também tão mágica quanto necessária, intermediada pelo corpo, destes sujeitos, depositário do estado de saúde ou de doença. Além do processo de transformação das mentalidades, são ainda levados em consideração os processos de construção, desconstrução e de evolução do imaginário e das representações sociais vivenciados pelos sujeitos e seus corpos. A evolução dos conhecimentos e o avanço científico-tecnológico são enfocados também como fontes modelares e comunicativas no sentido de ditar regras ao corpo que a humanidade porta socialmente neste século.
\end{abstract}

Palavras-chave: construção social da saúde, modelos de saúde, doença/corpo.

* Sociólogo, Doutor em Saúde Pública pela FSP/USP, Pós-Doutorado pelo CERMES/CNRS Paris, Professor AssistenteDoutor "Faculdade de Filosofia e Ciências" UNESP/Campus de Marilia. - Av. Higyno Muzzi Filho, 737 - CEP17525900 - MARÍLIA/SP 


\section{UM PROCESSO EM CONSTANTE CONSTRUÇÃO:}

No decorrer do processo histórico, principalmente nos séculos XIX e XX, uma multiplicidade de enfoques e de conceitos têm designado saúde como sendo a grande meta a ser alcançada, de acordo com os delineamentos da cultura que os homens constróem e reconstróem, formulam e reformulam nas mais diferentes sociedades e ideologias. Para tanto, ritualiza modelos que traduzem a saúde do seu tempo, prevendo, ao mesmo tempo, toda uma série e ordenações dos controles de riscos a que estão sujeitos. Neste sentido, lemos em VIGARELLO(1993:9) "o modelo de saúde que busca alguma 'verdade' deve poder ilustrar suas próprias fraquezas... ele deve poder revelar o ingovernável".

No desenrolar do referido percurso, modelos de saúde são sucessivamente propostos, bem como modelos corporais que os acompanham são constantemente permeados por uma visão alarmista sobre os riscos, implicando tanto na aquisição de cuidados quanto de preceitos sobre o cultivo da saúde, cuja finalidade é a de favorecer a manutenção de uma condição saudável de vida. Daí, a adoção de condutas básicas em torno da preservação do denominado estado de saúde.

\section{ORDEM E DESORDEM: CORPO E SAÚDE}

As controvérsias sugeridas a partir das pesquisas nos âmbitos da Sociologia, Antropologia e Saúde Pública têm demonstrado haver um continuado reprocessamento đos valores que estão diretamente ligados à ação de construçăo do conceito de saúde, para o qual têm sido considerados múltiplos enfoques advindos da religião, da ciência médica ou mesmo da cultura popular. Em cada um deles tem estado sempre presente tanto a identificação quanto o medo da ocorrência de novas doenças, 
pois, enquanto condição de fatores que oferecem risco à saúde, vêm estabelecendo modificações tanto sobre os modelos de saúde quanto o cultivo do corpo. Neste sentido, significativas alterações da qualidade de vida das sociedades acarretam, também.e fortemente, sensiveis mudanças nas formas de sentir, pensar e agir dos seus sujeitos e, consequentemente, provocam notáveis transformações no imaginário que constróem sobre saúde, frente às representações sociais das doenças.

Resultados cientificos oriundos de pesquisas multidisciplinares(CHAMMÉ, 1992,1994; HERZLICH, 1984; LE BRETON, 1982; MINAYO \& COIMBRA, 1993; PIERRET,J,) têm demonstrado que o binômio saúde/doença está condicionado à compreensão de como os homens estão socialmente organizados e participam do processo cultural que os envolve e influencia suas concepções e ações coletivas e individuais.

Tais investigações possibilitam ainda a compreensão das extensões e implicações da maneira como são socialmente construidos os conceitos de saúde e de doença compreendidos em suas contradições, reveladoras que as partes desta binariedade são essenciais e inseparáveis na constituição dos imaginários e das representações sociais(AIACH \& CĖBE, 1991; HERZLICH, 1984).

Assim, as manifestações dos estados de saúde ou doença expressadas em diferentes intensidades e através de distintos critérios, poderão ser explicitadas desde as condições das mais simples queixas, até as especificidades da poliqueixa CHAMMÉ, 1992. Tais condutas serão constantemente avaliadas e regulamentadas segundo os determinantes e critérios orgânicos e culturais, no sentido de buscarem pela lógica que orienta tanto a Ciência médica quanto as convenções sociais.

Na medida em que o sujeito, através de seu corpo exibe as condições de 
ordem ou de desordem nele instaladas, cabe-lhe, ainda, simbolicamente, a tarefa de apresentá-lo como se fosse um verdadeiro passaporte que permite ao seu portador efetuar e efetivar a ampliação ou restrição das suas relações interativas. Tais relações estarão constantemente sob verificação, mediante as condições de suspeição aos riscos de alteração do estado de saúde, que, uma vez instalado, nunca é considerado como definitivo, pois saúde e doença estão sempre numa condição tão provisória quanto suspeitável.

No decorrer dos séculos, as posições e condutas adotadas tanto pelos sujeitos adoecidos quanto pelos que ainda se dizem em estado de aceitável salubridade, bem como por parte dos tomadores de decisão nos processos de gerenciamento das políticas de saúde, verifica-se o aparecimento de regras e de modelos a cada tempo considerados higiênicos e adequados aos distintos projetos impostos às populações. São geradas imposições ao comportamento coletivo enquanto indicadores ideais visando seja exercido o controle das massas, buscando, autoritariamente, pelo exercício de uma pedagogia do bom comportamento sobre a coletividade em nome da manutenção do estado saudável dos sujeitos, ou, do não contágio de suas enfermidades.

Para tanto, o próprio sujeito social passa a se submeter a um processo de auto-vigilância policialesca verificadora da ordem dos seus equilibrios orgânicos. Conforme VIGARELLO(1993:10) na Idade Média, "simples espelho, o corpo repercute em cada uma de suas partes, ampliadas porém idênticas, que compõem o conjunto do mundo: as referências e sinais são 'acessiveis', 'naturais'. A certeza de um modelo de saúde tornase ai sensivel, quase exata". Assistimos, então, a uma série de combinações (de miasmas, alimentos, gestos, resguardos...) que propõem alcançar equilibrio do corpo, numa divisão equitativa entre os seus humores, com o objetivo de evitar perturbações consideradas perigosas enquanto fatores de risco de doenças e ameaça à longevidade. 


\section{O CORPO E A SOCIEDADE}

Diante do processo evolutivo da história da cultura, a concepção de saúde vai também sofrendo idêntica evolução. Enquanto a sociedade vai se tornando mais instrumentalizada, mais mecanizada, o corpo vai passando a ser visto sob a ótica das novas descobertas das ciências físico-químicas, tecnológicas e biológicas. A partir do século XVII, surgem os Tratados de Saúde (como o de Puericultura), onde a concepção de saúde sofre ajustamentos distintos, com ordenamentos próprios, adotando condutas de possiveis manipulações, de orientações e de intervenções voluntárias, promovendo ações mecânicas sobre o corpo no sentido de prevenir doenças.

O Projeto Sanitário concebido no século XVII, os gestos cada vez mais numerosos e diversificados de intervenção sobre o corpo, promovem e favorecem ações ditas preventivas e pró-saúde, através de procedimentos adotados principalmente pelas elites da época, baseados em práticas repetidas de purgatórios, vomitórios ou sangrias. Fixa-se então, a denominada Medicina mensal, tão bem descrita por SAINT-SIMON. (1928) e por D'AQUIN et cols.(1982), a qual prevê manutenção da saúde e prevenção de doenças, através de manipulações dos fluxos internos do organismo.

Enquanto as condutas sobre cuidados de saúde vão sendo idealizadas e impostas para os sujeitos, as instituições sociais identicamente acompanham as mudanças das propostas coletivas e vão se organizando e se reformulando na mesma direção. É assim que, por volta de 1750 , são configurados dois modelos de familia: a familia moderna e a familia proletária. Para cada uma delas, um modelo ideal e adequado de saúde!

No modelo de familia moderna, o treinamento de hábitos higiênicos era iniciado numa idade bastante precoce, antes mesmo de que a criança pudesse controlar 
seus esfincteres, pois o corpo, segundo o pensamento da burguesia européia das zonas urbanas, era considerado um produtor de imundicies... Completando as tarefas institucionais para este tipo de familia, o grande local de aprendizado era a escola, não olar!

A familia proletária apresentava outras características: as crianças eram amamentadas por suas mães - mulheres desnutridas e exaustas - os hábitos higiênicos eram negligenciados e igualmente o controle genital. As crianças eram criadas nas ruas e precocemente encaminhadas para as fábricas, pois a Revolução Industrial se fazia à custa do trabalho infantil e feminino.

Enfocando politicamente tal situação, na medida em que as condições iam mudando, filantropos e politicos liberais tentavam limitar as horas de trabalho de mulheres e crianças, enquanto na Grã Bretanha, mulheres da classe média visitavam mães da classe trabalhadora para instrui-las numa nova prática sobre saúde das crianças: a Puericultura (palavra criada pelo médico francês A.C.CARON em 1865). Os procedimentos descritos para esta fase estão, pois, bastante ligados às concepções mecânicas advindas das ciências naturais e atribuidas à saúde e ao corpo, sendo que a influência sobre eles é vista como se fosse exercida por fatores diretamente físicos e, seus efeitos... os mais insuspeitados.

Nesta concepção, que se estende por todo o século XVIII, a máquina (corpo) não dispõe de regulação interna. Ela não compensa seus desequilibrios. Ela suporta passivamente as ações vindas de fora. O perigo é tido como uma constante, onde a referência a uma mecânica corporal parece mesmo haver tornado indispensável, permanente, o sistema de vigilância encarregado de colocar a saúde em dia!

A experiência de saúde revela, mais que nunca, a infinidade do risco! Nesta 
ocasião, é concebido o modelo das pestes, as quais são concebidas como ações não identificadas, ou que não puderam ser evitadas e que, por conseguinte, são capazes de destruir os poros...

Ou seja: "tudo pode perturbar a máquina"! Segue-se uma numerosa lista de vigilância a respeito dos efeitos que possam vir a ser maléficos à saúde. A máquina, torna-se, assim, ainda mais ameaçada, embora mais controlável e, sem dúvida, mais governável, porém, muito mais frágil ! Por isso a vigilância se estende ao impossivel, com consequências bastante particulares que escapam até mesmo aos limites da ciência.

\section{EVOLUÇÃO DO CONHECIMENTO E O CORPO}

O século XIX começa pesando e medindo. Com isso, a Saúde Pública adquirirá caracteristicas mais definitivamente cientificas e atira, sobre o corpo social, como bem discute SCLIAR(1987) um olhar contábil Anteriormente, no século XVIII, enquanto na França tem lugar o movimento anticientífico caracterizado pela oposição à tradição matemática e materialista da ciência francesa, na Inglaterra, em contrapartida, cresce o interesse pelas matemáticas, pois a ciência inglesa desenvolvia-se sobretudo, à demanda da Revolução Industrial, da qual resultou de início, importante invento: o da máquina à vapor por James WATT (1736-1819).

Surgem os primeiros estudos estatísticos e seu relacionamento com estudos sobre a mortalidade e morbidade, que passaram a ser medidas, revelando dados que chamavam a atenção para as desigualdades entre as localidades denominadas sadias e as não sadias.

O pensamento estatístico foi adquirindo conotações que puderam demonstrar a importância e a potencialidade dos números: eles servem para revelar ou para ocultar, embora estatísticas de saúde não fossem suficientes para explicar os 
mecanismos que presidiam a gênese e a distribuição das doenças. Para que isso acontecesse, o raciocínio estatístico teria de ser necessariamente ampliado com as observações colhidas nos locais onde as doenças ocorriam, ou seja, um raciocínio mais dinâmico: o da visão epidemiológica.

A mudança ocorrida na metodologia do estudo das enfermidades permitiu ampliação do conhecimento sobre os fatores e determinantes da saúde e da doença e se voltaram, no século XIX, para estudos que demonstravam que as taxas de mortalidade estavam ligadas às condições de vida, que era possivel e viável estabelecer correlacionamento entre epidemias e desigualdades sociais, que os denominados surtos, tinham periodos de incubação e de disseminação, que havia relação entre duração da imunidade adquirida, idade e gravidade da doença... Neste momento foi possivel a utilização dos métodos quantitativos para demonstrar diferenças entre grupos sociais onde as doenças ocorriam.

Durante a segunda metade do século XIX assistimos a uma outra orientação da concepção sobre saúde, devido à evocação da presença microbiana. O laboratório transformou as ordens do saber! A experiência transformou, igualmente, o registro das certezas comprovadas. Os micróbios são agora observados, seu número podendo ser calculado, seu efeito torna-se previsto! A sua mensuraçăo vem inverter o poder sobre o risco. Sua análise elimina os antigos sinais, pois provas e verificações são reforçadas.

Neste momento, o jogo a ser estabelecido com a não governabilidade do corpo torna tal condição enriquecida, desenvolvida, aprofundada, favorecendo uma total recolocação dos antigos conceitos. Só por volta de 1870 é que a microbiologia promove - controle reforçado do corpo, reorientando as ações destinadas à sua proteção e simplificando as medidas preventivas, onde um amplo conjunto de antigas preocupações tornam-se inúteis e sem sentido. A proteção das feridas, por exemplo, não supõe agora 
uma prospecção infinita de miasmas ambientais, mas prevê o imediato cuidado antisséptico da região lesada. A ação preventiva, torna-se, então, precisa.

Mediante a evolução dos recursos dos instrumentos de precisão da época (o microscópio a partir de 1880), a vigilância sanitária passava a ser focalizada sobre ameaças circunscritas, verificáveis, quase experimentais. Uma avidez pelos números e pelas constatações, faz nascer, então, um novo e infinito estado de medos! O mundo passa a ser visto segundo as ameaças que parecem, agora, pulular bruscamente nos locais mais recônditos da realidade, como sendo partes do invisivel em sua condição adormecida e acumulada...

Condição reveladora da mentalidade da época, em lugar do sujeito tornarse o exclusivo responsável pelas falhas na vigilância e cuidados com relação à sua própria saúde, ou mesmo de atribuir a Deus a responsabilidade da intermediação sobre seu corpo-máquina, o inimigo, desta vez, vem sorrateiro e se instala e se mantém nas menores dimensões internas e externas do organismo (desde os poros até a saliva) e, por isto, são então concebidos como verdadeiros invasores!

Os recenseamentos extravagantes, dispersos, laboriosos, sugerem, no final do século XIX, novas práticas, gestos precisos e iguais inquietudes. Os delírios dos contágios tornam-se a versão extrema de preocupações multiplicadas, pois o conhecimento da existência dos micróbios renova totalmente a visão da impotência sanitária, atribuindo-Ihe, até, muitas vezes, a força de uma obsessão.

Assiste-se, na época, a uma notável mudança sobre o poderoso instrumental cientifico que se instala e que, em contrapartida à própria revelação de Pasteur, parece, neste momento, estar sendo instalada uma verdadeira revelação da "microbiomania"1

' O termo "microbiomania" é utilizado por SCLIAR (1987). 
como resultado do progresso científico. Assim, naquele final de século, os fatores ameaçadores passam a ser reconhecidos em sua fragilidade que vai se tornando cada vez mais objetiva, pois um desenvolvimento quase lógico se impõe nestas condições, outrora atribuidas ao impossivel e que, neste momento, mediante a amplitude e difusão do conhecimento científico, que se torna público, vai favorecendo a objetivação sobre os males, assegurando aos sujeitos um maior poder e domínio sobre seu próprio corpo.

A instrumentalização do conhecimento higiênico e microbiológico ocorrido na segunda metade do século XIX, sua nova complexidade e precisão, criam uma situação bastante peculiar: a do entrecruzamento de uma multiplicidade de saberes intermediários entre os conhecimentos eruditos e os outros conhecimentos. Nesta mesma época, todos sabem de onde vêm os perigos recém descobertos e, ato contínuo, um novo estabelecimento se impõe ao imaginário coletivo. É quando damas de caridade "se recusam em visitar os doentes; os proprietários de imóveis em Paris recusam alugá-los aos médicos ou até exigem que os doentes transitem pelas escadas de serviços. Todos se acham influenciados pelos conhecimentos recentes sobre os micróbios.."(SCLIAR, 1987).

Os números, mais que nunca, sugerem o medo. Ocorre, sem dúvida, uma maneira de reforçar a imagem da instituição saúde, tanto quanto os estatutos de higiene da época. Até mesmo as grandes metáforas sobre os micróbios, suscitadas pelas tensões sociais e políticas do final do século XIX desempenham um papel nesta ilustração.

A concepção de saúde assume, aqui, a imagem de um "verdadeiro império" nas palavras de VIGARELLO(1993), com seus conflitos, seus assaltos, sua polícia e seus exércitos.

Numa total inversão de posições, o indivíduo, mais que nunca, torna-se 
responsável pela degenerescência ou pelo imprevisto coletivo. A defesa de si mesmo concorre com a dos outros sujeitos, conforme querem assinalar as politicas do final daquele século, tanto quanto os microbiologistas.

\section{A NOVA VISÃO DE CORPO}

O século XX passa a ser reconhecido como tempo dos flagelos! A partir da Revolução Industrial, cidades e áreas industriais cresceram rapidamente sem nenhum planejamento, tornando-se carentes dos mais elementares equipamentos sanitários, desde o abastecimento de água, de esgoto, coleta de lixo e higiene da habitação.

A questão social surgida com a Revolução Industrial representa o fim da concepção orgânica, hegeliana, da sociedade e do Estado e a saúde torna-se, uma questão pública. Este fato é revelado pelo desencadeamento de ações políticas por parte de algumas sociedades que, a partir das avaliações das doenças, procuram administrar os índices de saúde. Como exemplos clássicos de tais providências, temos o da organização do Sistema Previdenciário na Alemanha - pelo príncipe Otto VON BISMARCK - que se estende para a França e Inglaterra, assumindo em cada país uma conotação especifica, influenciando ainda, extensivamente, nas decisões de criação do Seguro Social brasileiro no governo de Vargas, nos anos 30 e 40.

Tal situação influencia diferentes modelos de saúde e de corpo considerados ideais nas distintas décadas do século $\mathrm{XX}$, cujo estilo atinge tanto o corpo dos adultos quanto o das crianças.

Posteriormente às instalações, transformações e unificações legais propostas pelas organizações previdenciárias, foram sendo estabelecidas orientações que diretamente diziam respeito à Saúde Pública, exigindo, para tanto, um planejamento das ações em saúde. 
Paralelamente, as Políticas de Saúde preparam internacionalmente orientações de ações individuais e de condutas coletivas, vertidas sob a forma de Planejamentos em Saúde a serem adotadas pelas populações mundiais, no sentido de prevenir doenças e de buscar por um estado de saúde adequado a cada tempo. Esta situação se traduz nos diferentes modelos de saúde e de corpo que foram típicos em diferentes décadas do século XX. Assistimos, assim, a um desfilar de corpos moldados segundo orientações do pensamento romântico, rebelde, comedido, recatado, revolucionário, despojado, insinuante, "sexy", "fatalista".. A cada um deles, correspondendo sempre o risco de uma doença considerada fatal, no geral exuberante, culminando em estados de agonia e de morte igualmente típicos.

Concomitante ao estilo e aos riscos da vida e dos corpos adultos, os Planejamentos em Saúde propuseram também às crianças de cada um destes períodos, modelos de infância saudável, que, se seguidos à risca, seriam promissoras a um futuro contingente adulto igualmente saudável ! É o caso do modelito Bebê Johnson idealizado sobre a figura de um bebê do sexo masculino, branco, louro, olhos azuis, de feições suaves qual um anjo barroco, aureolado pela meiguice, robusto, traduzindo elevado peso ao nascer, teor nutricional previsto com excesso de calorias, garantindo-lhe contornos arredondados e pequenos "furinhos" sobre as mãozinhas de pele alva e rosada... Ato contínuo, a preocupação dos pais em superalimentar seus bebês, garantindo assim a manutenção e ampliação de todo um esquema da indústria nutricional para a primeira infância, substituição do aleitamento materno por superdosagens de leite em pó e açúcares especificos...

Enfim, superdosagens energéticas e a geração de adultos de compleição obesa e, consequentemente, os problemas e riscos dos acidentes vasculares e... a criação de nova indústria: agora as orientadas pela Endocrinologia, as Clínicas de emagrecimento, os Spa! 
Atualmente, alertados pelos problemas de saúde, criados muitas vezes pelo medo de doenças e até mesmo pelo excesso de zelo, o avanço da Ciência Médica bem como a ampliação das áreas de investigação das Ciências Sociais, saúde/doença/corpo foram sendo enfocados, principalmente a partir das últimas décadas deste século, não mais pela ótica exclusiva das ciências biológicas, suas regras ou formas de legitimação mas segundo uma visão ampliada que alcança o campo da multidisciplinaridade. Assim, a compreensão dos fatores que determinam ou caracterizam o discutivel estado de saúde, encaminham a questão na direção das condições a que o corpo do sujeito está submetido, principalmente as dos distintos niveis da qualidade de vida que o sustém.

As preocupações então sugeridas, ultrapassam a condição do estado de saúde como uma mera aferição do estado de adoecimento e, o corpo, é indagado em sua dimensão biopsicossocial e seu portador passa a ser visto enquanto totalidade dinâmica e integrada ao ambiente que o cerca.

"Temos ou somos nosso corpo?" é o questionamento elaborado por RICHIR(1993), evidenciando que o interesse científico atual no sentido de buscar pela compreensão da condição de saúde está além das condições imediatamente oferecidas pelos dados subjetivos das doenças (sintomas) ou até mesmo os objetivos (sinais), reveladores de sua simples presença ou ausência.

Reconhece-se, assim, que a experiência do corpo poderá nortear-se entre dois pólos (o de saúde e o de doença), porém seus determinantes não serão necessariamente ditados pela exclusividade do acometimento biológico, mas também pelas condições culturais e simbólicas que configuram sua ampla e complexa identidade.

Corpo enquanto depositário de saúde ou doença tem sido indagado, portanto, neste final de século, para além dos riscos biológicos a que está exposto, mas como 
extensão do sucesso ou insucesso da força do coletivo e do poder individual direcionado na elaboração de seu controle. Neste momento da História Social devemos, pois, considerar saúde e doença não mais situações vistas com independência ou isoladamente, mas como fazendo parte de um "continuum" integrado entre saúde/doença/ corpo.

\section{REFERÊNCIA BIBLIOGRÁFICA}

ADAM, P. \& HERZLICH, C.I. Sociologie de la maladie et de la médecine. Paris, Nathan, 1994.

Al̈ACH, \& CĖBE, Expression des symptômes et conduites de maladies. Paris, Doin, 1991.

ALVES, P.C. \& MINAYO, M.C.S. org Saúde e doença: um olhar antropológico. Rio de Janeiro, Ed. FIOCRUZ, 1994.

ARIĖS, P. História social da criança e da família. Rio de Janeiro, Zahar, 1978.

AUGÉ, M. \& HERZLICH, C.I. Le sens du mal; anthropologie, histoire, sociologie de la maladie. Paris, Éd. des Archives Contemporaines, 1984.

BERTHELOT, J.M. Du corps comme opérateur discursif ou les apories d'une sociologie du corps. Sociol. et Soc., 24(1):19-29, 1992.

BOLTANSKY, L. La souffrance à distance: morale humanitaire, médias et politique. Paris, A.M.Métaillié, 1993.

CHAMMÉ, S.J. Poliqueixoso: metáfora ou realidade? São Paulo, 1992. [Faculdade de Saúde Pública, USP].

CHAMMÉ,S.J. Educação para a doença. Saúde em Debate, (44):32-34, 1994.

D'AQUIN, A., TAGON, G-C., et VALLOT, A. Journal de santé du roi Louis XIV (1647 - 1711). Paris, 1862. p.109-115.

DE LA FRANBOSIĖRE, N.A. Le gouvernement nécéssaire à chacun pour vivre 
longuement. Paris, 1600.

DELUMEAU, J. A confissão e o perdão. São Paulo, Cia. das Letras, 1991.

DUJARDIN-BEAUMETZ, L'hygiène prophylactique. Paris, 1889.

HERZLICH, C.I. Santé et maladie; analyse d'une représentation sociale. Paris, Ed. de I'EHESS, 1984.

HERZLICH \& PIERRET. De ayer a hoy: construcción social del enfermo. Cuad. MédSOC., (43):21-30, 1988.

LE BRETON, D. Corps et symbolique sociale. Cah. Int. Soc., 83:, 1982.

MINAYO, M.C.S. \& COIMBRA Jr.,C.E.A. As abordagens antropológicas em saúde. Cad.Saúde Pública, 9, 1993.

PIERRET, J. Les significations sociales de la santé: Paris, L'Essonne, L'Herault. apud AUGÉ \& HERZLICH, op.cit., p.217-256.

RICHIR, M. Le corps: essai sur l'intériorité. Paris, HATIER, 1993.

ROCHARD, J. Traité d'hygiène publique et privé. Paris, 1897.

SAINT SIMON, duc de. Mémoires. Paris, Hachette, 1928 (Ed. Boislisle, t.XXVII).

SCHLANGER, J. Les métaphores de l'organisme. Paris, Vrin, 1971.

SCLIAR, M. Do mágico ao social: a trajetória da saúde pública. São Paulo, L\&PM, 1987.

UNGLERT, C.V.S. Territorialização em saúde: a conquista do espaço local enquanto prática do planejamento ascendente. São Paulo, 1995. [Tese de Livre-Docência - Faculdade de Saúde Pública da USP].

VIGARELLO, G. Modèles anciens et modernes d'entretien de la santé. In: COMMUNICATIONS, Paris, EHESS, Centre d'Études Transdisci plinaires, 56, 1993. 
Summary: The present article aims at understanding the process of "Social Construction in Health" bearing in mind that health has, along the history of mankind, been always considered a good. It has thus been of constant concern in that it becomes the generator of trends, modes of doing and existing, conflicts, dualities and social control. Along that time health models were designed, interpreted and recreated when necessary, leading to a similar transformation process in the forms of feeling and acting of the users of the most varied health resources available. This is done within the relation between the "magic and the necessary" establishing between those who serve and who were served a relation also as magic as necessary which is intermediated by the body of those subjects, depositary of health and illness states. Besides the transformation process of mentalities also taken into consideration are the processes of construction, deconstruction and evolution of the imaginary and the social representations experienced by the subjects and their bodies. The evolution of knowledge and technical and scientific advances are also focused as model and communicative sources in the sense of dictating rules to the body that humanity socially bears in this century.

Key words: Social construction in Health, health models, ilness/body 